Çukurova Üniversitesi Mühendislik Mimarlık Fakültesi Dergisi, 33(1), ss. 47-54, Mart 2018

Çukurova University Journal of the Faculty of Engineering and Architecture, 33(1), pp. 47-54, March 2018

\title{
Balıklıgöl Havzası Su Kaynaklarının Nitrat ve Nitrit Seviyelerinin Belirlenmesi
}

\author{
Recep YETIŞs ${ }^{* 1}$, A. Dilek ATASOY ${ }^{2}$, Ayșegül DEMIR YETIŞş, \\ M. İrfan YEŞiLNACAR ${ }^{2}$ \\ ${ }^{1}$ Bitlis Eren Üniversitesi, Sağllk Hizmetleri Meslek Yüksekokulu, Bitlis \\ ${ }^{2}$ Harran Üniversitesi, Çevre Mühendisliği Bölümü, Şanlıurfa \\ ${ }^{3}$ Bitlis Eren Üniversitesi, Çevre Mühendisliği Bölümü, Bitlis
}

$\ddot{\mathbf{O z}}$

Gelis tarihi: 13.11 .2017

Kabul tarihi: 14.03 .2018

\begin{abstract}
Balıklıgöl Havzası Şanlıurfa İli sınırları içerisinde yer almaktadır. Balıklıgöl Havza'sındaki bu çalışma havza sınırı içerisinde bazı su kaynaklarında nitrat ve nitrit seviyelerinin araştıılması maksadıyla yapılmıştır. Çünkü su kaynaklarında nitrat ve nitrit açısından olması muhtemel bir kirlilik öncelikli olarak o bölgedeki ve civarındaki su kaynaklarını kirleterek dolaylı olarak bu suyu tüketen insanların da sağlığını olumsuz etkileyecektir. Bu nedenle Nisan 2014 - Ocak 2015 tarihleri arasında yapılan çalışma bir yıl boyunca mevsimlik olarak 8 ayrı noktada yürütülmüştür. Havzadan alınan numunelerde nitrat ve nitrit analizleri spektrofotometrik yöntemle yapılmıştır. Sonuç olarak, su numunelerinde nitrat en düşük $1,52 \mathrm{mg} / \mathrm{L}$, en yüksek $15,9 \mathrm{mg} / \mathrm{L}$ olarak tespit edilmişken; nitrit ise en düşük $0,014 \mathrm{mg} / \mathrm{L}$, en yüksek $0,203 \mathrm{mg} / \mathrm{L}$ olarak ölçülmüştür. Elde edilen nitrat ve nitrit sonuçlarına ait alansal dağılım haritası oluşturulmuştur. Ayrıca ulusal ve uluslararası standart ve sinıflamalara tabi tutularak değerlendirilmiştir.
\end{abstract}

Anahtar Kelimeler: Nitrat kirlenmesi, Nitrit kirlenmesi, Balıklıgöl Havzası, Coğrafi bilgi sistemleri

\section{Determination of Nitrate and Nitrite Levels of Water Resources in Balikligol Basin}

\begin{abstract}
Balikligol Basin is located within the borders of Sanliurfa Province. This study in Balıklıgöl Basin was conducted to investigate nitrate and nitrite levels in some water sources within the watershed boundary. Because a potential pollution in the water resources in terms of nitrate and nitrite will directly pollute the water resources in and around that region; indirectly adversely affect the health of people who consume that contaminated water. For this reason, the study conducted between April 2014 - January 2015 was carried out in 8 different locations seasonally. Nitrate and nitrite analyzes were performed spectrophotometrically in samples taken from the basin. Consequently, nitrate in water samples was measured as lowest $1.52 \mathrm{mg} / \mathrm{L}$, highest $15.9 \mathrm{mg} / \mathrm{L}$; while nitrite was measured as lowest $0.014 \mathrm{mg} / \mathrm{L}$ as the highest and $0.203 \mathrm{mg} / \mathrm{L}$. Spatial distribution map of the obtained results of nitrate and nitrite was formed. In addition, the results have been evaluated subject to national and international standards and classifications.
\end{abstract}

Keywords: Nitrate pollution, Nitrite pollution, Balikligol Basin, Geographic information systems

*Sorumlu yazar (Corresponding author): Recep YETiş, ryetis@beu.edu.tr 


\section{GíRiş}

Dünya nüfusunun artı̧s, kentleşme, teknolojinin her geçen gün hızlı gelişmesine bağlı olarak endüstriyel, tarımsal ve diğer faaliyetler sonucunda oluşan katı atıklar ve atık sular doğaya verilerek büyük problemlerin ortaya çıkmasına sebep olmuştur [1]. Evsel, endüstriyel, tarımsal atıklar ve bilhassa azot içerikli gübrelerin büyük ölçekte kullanılmas1; yeraltı suyu, toprak ve tarımsal ürünlerdeki azot miktarının artışına neden olur $[2,3]$. Yeraltı sularına yüksek azot girdileri nitrat ve nitrit konsatrasyonlarını arttırmaktadır [4,5]. Nitrat ve nitrit tabiatın her yerinde karşımıza kolayca çıkabilen parametrelerdendir. Bunlar azot döngüsünün nitrifikasyon kademesinde, azot tutucu bakteriler vasıtasıyla doğal bir şekilde oluşan inorganik iyonlardır [6,7]. Hiç bir işlem görmeden içme ve kullanma suyu olarak değerlendirilen dünyanın en büyük tatlı su kaynağı olan yeraltı sularında, nitrat ve nitritin kontaminasyonuyla su kalitesinde bozulma ve bu suyu kullananlarda kronik rahatsızlıklar görülmektedir [8]. $\mathrm{Bu}$ nedenle yeraltı su kaynaklarının kalitesini bilmek önemlidir.

Nitrit bir geçiş fazı olduğundan sularda çok az bulunan bir iyondur [9]. Nitratlar, nitritlere indirgenebildikleri ölçüde toksik olur ve kanserojen olan nitrozaminlerin yapısına katılır [10]. İnsanların aldığı nitrat nitrite çevrilmekte veya direk olarak fazla oranda alınan nitrit dolaşım sisteminde methemoglobin ( $\mathrm{MHb}$ ) oluşumunu artırmakta ve eritrositlerin oksijen taşıma hacmini düşürerek hipoksi, vazodilatas gibi sorunlara sebep olmaktadır [11-13]. Bazı ülkeler tarafından nitrat ve nitrit konsantrasyonlarının toplum sağlığına zararlı tesirlerini azaltmak amacıyla birçok düzenlemeler yapılmıştır. Avrupa Birliği ülkeleri ve Türkiye'de içme ve kullanma sularında var olan azami nitrat ve nitrit konsantrasyonları sirasiyla $50 \mathrm{mg} / \mathrm{L}$ ve $0,50 \mathrm{mg} / \mathrm{L}$ olarak belirlenmiş̧iir [6].
$\mathrm{Bu}$ çalışma, son zamanlarda kentleşme, tarım ve turizm faaliyetlerinden yoğun olarak etkilenen Balıklıgöl Havzası'nda içme ve kullanma suyu olarak kullanılan kuyuların ve turistik amaçlı olarak yoğun ziyaretçi alan Balıklıgöl kaynağının havzadaki çıkış noktalarının nitrat ve nitrit düzeylerinin araştırılması maksadıyla yapılmıştır.

\section{MATERYAL VE METOT}

\section{1. Çalış̧ma Alanı}

Balıklıgöl havzası Şanlıurfa İli sınırları içerisinde olup, doğuda 468076 E-4111534 N; batıda 464510 E ve $4118983 \mathrm{~N}$; kuzeyde $467482 \mathrm{E}$ ve 4122669 $\mathrm{N}$; güneyde ise $476309 \mathrm{E}$ ve $4107848 \mathrm{~N}$ enlem ve boylamları arasında kalmaktadır. Havza doğuda Hasanpaşa Cami, batıda Büyükalanlı Köyü, kuzeyde Hisarlar Köyü ve güneyde Kadıkendi Köyü ile çevrilidir. Büyüklüğü yaklaşı $17 \mathrm{~km} \times 5 \mathrm{~km}$ olup, ilin kuzeybatısında bulunmaktadır (Şekil 1).

Bölgenin ortalama yüksekliği 548 m'dir. Balıklıgöl Havzası kurak-yarı kurak bir iklim özelliğine sahip olup; yıllık ortalama yağış miktarı $284,2 \mathrm{~mm}$, sıcaklık $18^{\circ} \mathrm{C}$ ve buharlaşma oranı ise $1,884 \mathrm{~mm}$ 'dir [14,15]. Bölgede gözlenen en önemli ve en aktif fay Bozova fayıdır [16]. Kuzeybatı ve güneydoğu güzergâhında bu fay zonu boyunca oluşumunun tamamlandığı tartışılan Karakoyun Deresi ve onun oluşturduğu vadi, alüvyon birikinti malzeme ile kaplıdır. Bu derenin etrafinda bölgede en sı rastlanılan Midyat kireçtaşı formasyonu [17] kayaçlarının oluşturduğu orta yükseklikte tepeler bulunmaktadır. Vadinin kuzeybatısındaki Direkli ve güneydoğusundaki Balıklıgöl kaynakları olmak üzere iki ayrı yeraltı suyu boşalımı bu havzada görülmektedir. DSİ tarafindan yapılan jeolojik incelemeler ve zemin etüdü sonucuna göre bölgede akifer özelliği taşıyan ve yeraltı suyunun bulunduğu kayaç, Eosen yaşlı Midyat kireçtaşı formasyonudur. 


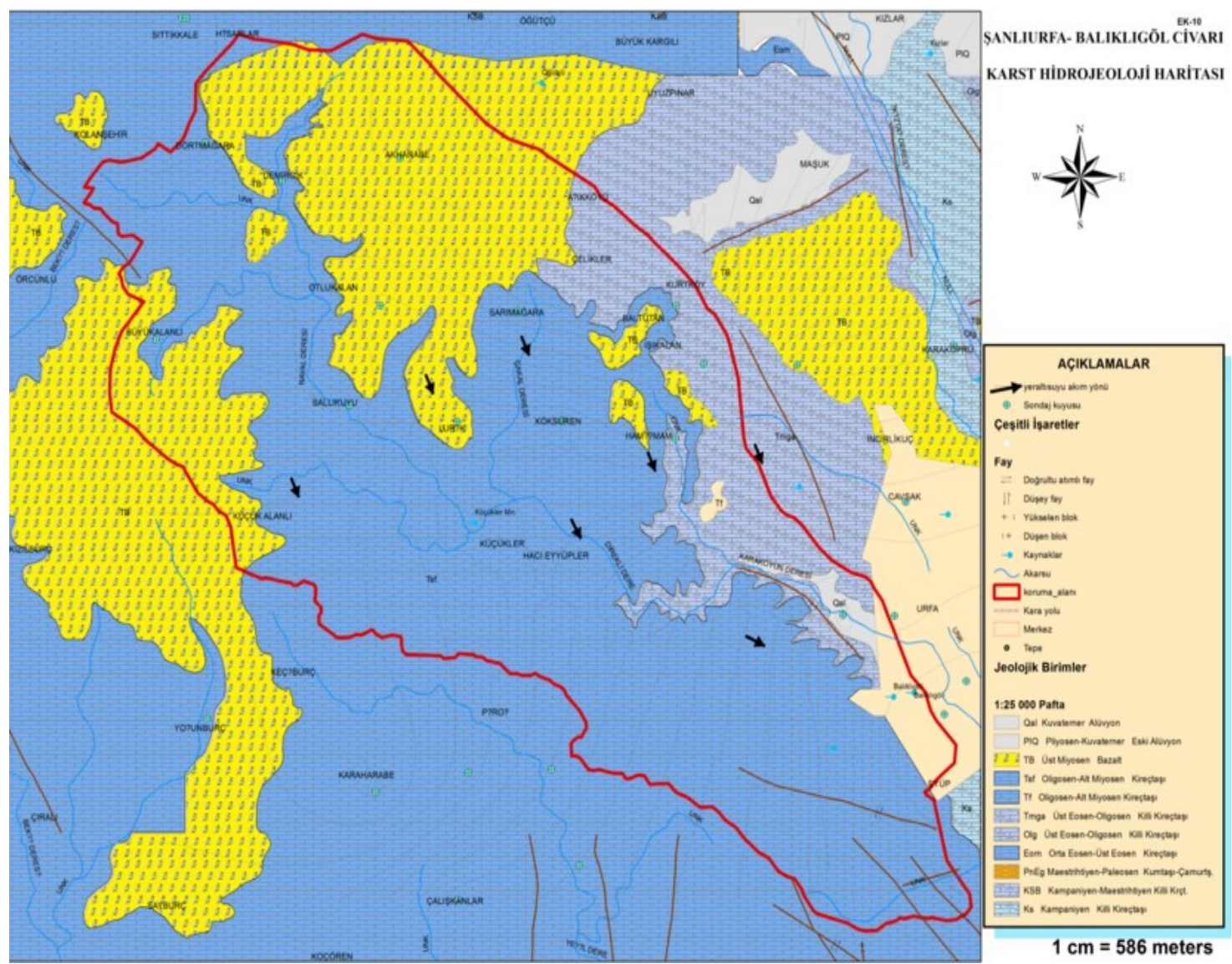

Şekil 1. Şanlıurfa-Balıklıgöl havza sınırını gösterir Karst Hidroloji haritası [15,18]

\subsection{Arazi ve Numune Alma Çalışmaları}

Balıklıgöl Havza sınırını en iyi temsil eden ve numune almaya uygun olan Lüleci, Köksüren, Direkli, SSK, Beyazsaray aktif kuyuları ve havzanın çıkış noktaları olan Döşeme Cami, Aynzeliha ve Dergâh kaynakları numune noktaları olarak tespit edilmiştir. Bu çerçevede 8 noktadan 1 yıl süreyle mevsimsel (Nisan 2014-Ocak 2015) olarak, Balıklıgöl Havzası su kaynaklarında nitrat ve nitrit ölçümleri yapılmıştır. Numune alınan noktalara ait koordinatlar Çizelge 1'de, havzanın coğrafik konumu ve numune alma noktalarının lokasyonları Şekil 2'de sunulmuştur. Arazi çalışmalarında numune toplama işlemi standart metotlara [19] uygun olarak yapılmıştır. Buna göre plastik şişelere alınan su numuneleri aynı gün içerisinde analiz edilmek üzere Şanlıurfa Belediyesi İçme suyu Arıtma Tesisi Çevre Kimyası Laboratuvarına getirilmiştir.

Çizelge 1. Numune alma noktaları ve koordinatları

\begin{tabular}{|l|l|c|c|}
\hline \multirow{2}{*}{ No } & \multirow{2}{*}{$\begin{array}{c}\text { Numune } \\
\text { noktaları }\end{array}$} & \multicolumn{2}{|c|}{ Koordinatlar } \\
\cline { 3 - 4 } & & $\mathbf{X}$ & Y \\
\hline N1 & Lüleci & 472268 & 4116062 \\
\hline N2 & Köksüren & 474216 & 4116128 \\
\hline N3 & Direkli & 477618 & 4113530 \\
\hline N4 & SSK & 479998 & 4112148 \\
\hline N5 & Beyazsaray & 480665 & 4111534 \\
\hline N6 & Döşeme Cami & 480788 & 4111301 \\
\hline N7 & Aynzeliha & 480917 & 4111178 \\
\hline N8 & Dergah & 481057 & 4111161 \\
\hline
\end{tabular}




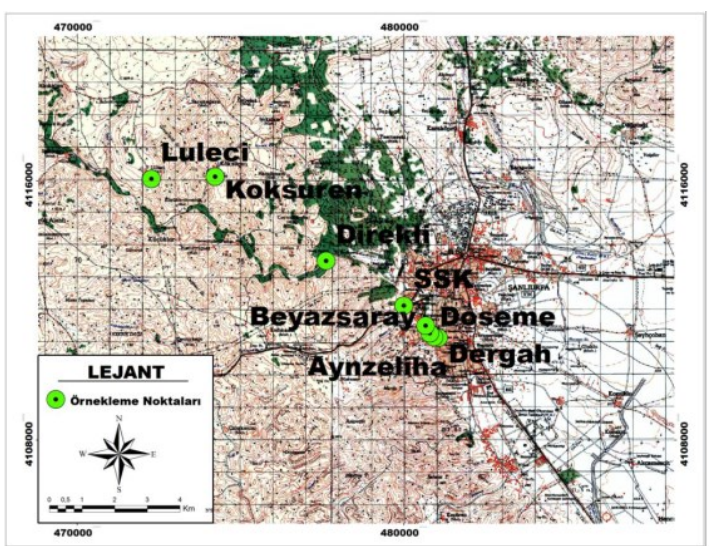

Şekil 2. Çalışma alanına ait coğrafik görünüm ve örnek alma noktaları [4]

\subsection{Haritalama ve Metot}

Havzadan toplanan numunelerin nitrat ve nitrit ölçümleri sırasıyla Cadmium Reduction Method ve Diazotization Method ile spektrofotometrik olarak yapılmıştır [26]. Elektriksel İletkenlik (EC), sıcaklık ve pH ölçümleri WTW marka taşınabilir EC metre ve $\mathrm{pH}$ metre cihazları ile arazide ölçülmüştür. Çalışma sahasına ait altlık olarak kullanılacak topografik harita paftaları Coğrafi Bilgi Sistemi ArcGIS ArcMap 10.1'de koordinatlandırılmış ve numune alma noktalarına ait koordinatlar bu haritalar üzerine işlenmiştir. Arazi çalışmaları tamamlandıktan sonra, elde edilen nitrat ve nitrit sonuçlarına ait alansal dağılım haritaları Surfer Version 13.00 Golden Software, Inc yazılımı yardımıyla oluşturulmuştur. Ayrıca nitrat ve nitrit sonuçlarının SPSS 16.0 paket programı kullanılarak tanımlayıcı istatistik bilgileri sunulmuştur. Son olarak sonuçlar TS266 Sular-İnsani Tüketim Amaçlı Sular, İnsani Tüketim Amaçlı Sular Hakkında Yönetmelik [20], Dünya Sağlı Örgütü (WHO) [13] ve Çevre Koruma Ajansı (EPA) [21] gibi ulusal ve uluslararası standart ve sinıflamalara tabi tutularak değerlendirilmiştir.

\section{BULGULAR VE TARTIŞMA}

Balıklıgöl Havzası'nı temsil eden su kaynaklarında 2014-2015 yılları arasında mevsimsel olarak 8 noktadan numune alma çalışmaları yapılmıştır.
Buna göre toplanan numunelerde nitrat ve nitrit parametrelerinin değerlerini araştırmak üzere ölçümler yapılmıştır. Ayrıca numunelerin EC, sıcaklık ve $\mathrm{pH}$ değerlerine ait ölçümler yerinde gerçekleştirilmiştir.

\subsection{Su Sicaklığı}

Çalışma alanındaki yeraltı sularının sıcaklık değerleri 14 ile $25,5{ }^{\circ} \mathrm{C}$ arasında değişmekte olup, Dişli ve ark. tarafından 2003 'te yapılan çalışmada aynı noktalarından elde edilen veriler birbirleriyle benzerlik göstermektedir [23]. Şahinci [22]'nin yaptığı çalışmaya göre su sıcaklıklı değerleri 'Çok az 1lik sular' ve 'Az 1lik sular' kapsamına girmektedir. Sıcaklığın mevsimsel değişimi Şekil 3 'te görülmektedir.

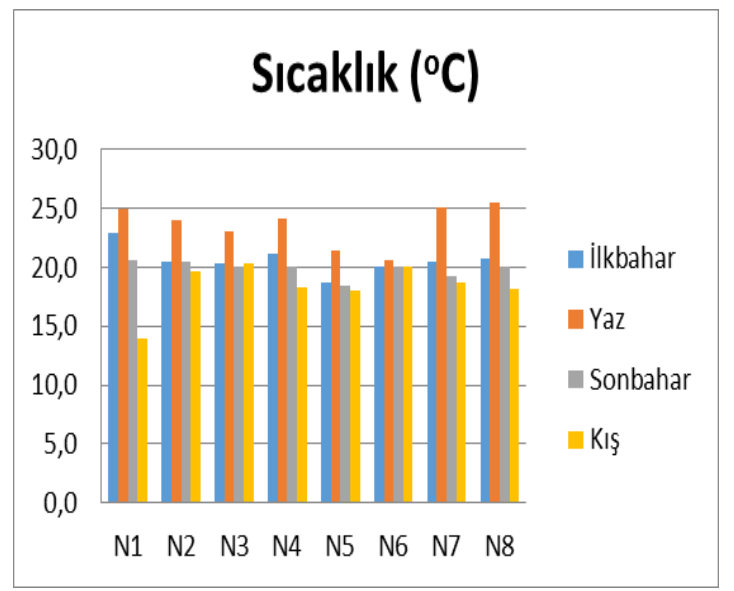

Şekil 3. Sıcaklığın numune alma noktalarına göre mevsimsel değişimi

N1-N4 örnek alma noktaları ve bu noktalar arasında bulunan N2, N3 noktaları yeraltı sularını temsil ettiğinden su sicaklıkları mevsimlik olarak pek değişiklik göstermemektedir. N5-N8 örnek alma noktaları ve bu noktalar arasinda bulunan N6, N7 noktalarından alınan örnekler kaynak suları olup yüzeyden alındığı için mevsimlik olarak hava değişikliğinden etkilenmektedir.

\subsection{Elektriksel İletkenlik}

Çalışma alanındaki yeraltı suyu örneklerinin EC değeri 319 ile $820 \mu \mathrm{S} / \mathrm{cm}$ arasında değişmekte 
olup, Dişli ve arkadaşlarının 2003'te [23], Armağan ve arkadaşlarının da 2008'de [24] yaptığ çalışmalarında aynı noktalardan elde edilen sonuçlarla kıyaslandığında çok az bir artış olduğu belirtilmiştir. TS(266)'da $20{ }^{\circ} \mathrm{C}$ 'de EC değerinin suyun sınıfina ve tipine göre en çok 650 ve $2500 \mu \mathrm{S} / \mathrm{cm}$ arasında müsaade edilen değerler olduğu belirtilmiştir. EC için WHO ve EPA'ya göre istenen limit değerler sırasıyla $1500 \mu \mathrm{S} / \mathrm{cm}$ ve $250 \mu \mathrm{S} / \mathrm{cm}$ 'dir $[13,20,21]$. Elde edilen bu sonuçlara göre çalışma alanında düşük EC, yeraltı sularında tuzların düşük olduğunun göstergesidir [2]. Elektriksel iletkenliğin mevsimsel değişimi Şekil 4'te görülmektedir.

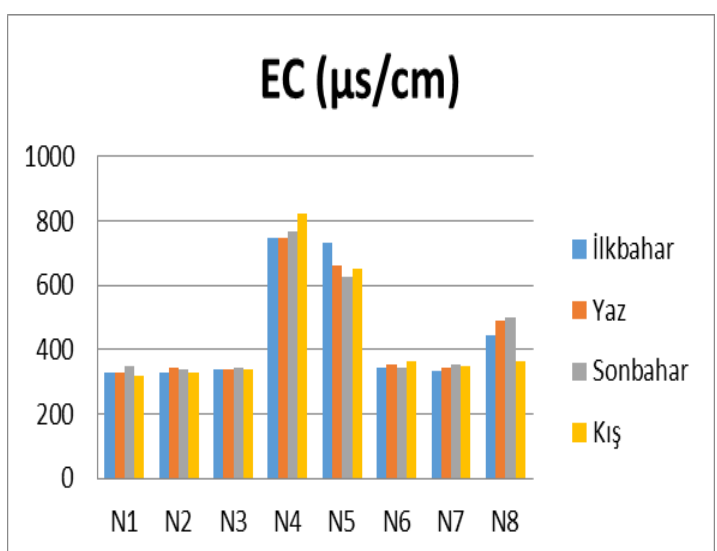

Şekil 4. Elektriksel iletkenliğin numune alma noktalarına göre mevsimsel değişimi

Buna göre EC parametresi ele alındığında değerler mevsimsel olarak fazla değişim göstermemektedir. N1, N2, N3, N6, N7 noktalarında yapılan ölçümler birbirlerine yakınlık göstermektedir. N4 ve N5 noktalarında EC değerlerinin yüksekliğinin nedeni; bu noktalara yakın yerlerde kanalizasyon sistemlerinden sızan atık suların yeraltı suyuna karışarak tuzluluk miktarını artırdığı düşünülmektedir.

\subsection{Ph}

Çalışma alanındaki yeraltı suyu örneklerinin $\mathrm{pH}$ değeri 7,11 ile 7,89 arasında değişmekte olup, bu da bölgedeki yeraltı sularının pH'ının genelde hafif alkali olduğunu göstermektedir. Dişli ve arkadaşları (2004) ve Armağan ve arkadaşları (2008) tarafından yapılan çalışmalarda aynı lokasyonlardaki sonuçlarla benzerlikler belirlenmiştir [24,25]. pH sonuçları; TSE (266) standardı, Su Kirliliği Kontrolü Yönetmeliği, WHO ve EPA'nın 6,5-9,5 olan müsaade edilebilir sınır değerleri arasında bulunmuştur [13,20,21]. pH'ın mevsimsel değişimi Şekil 5'te görülmektedir.

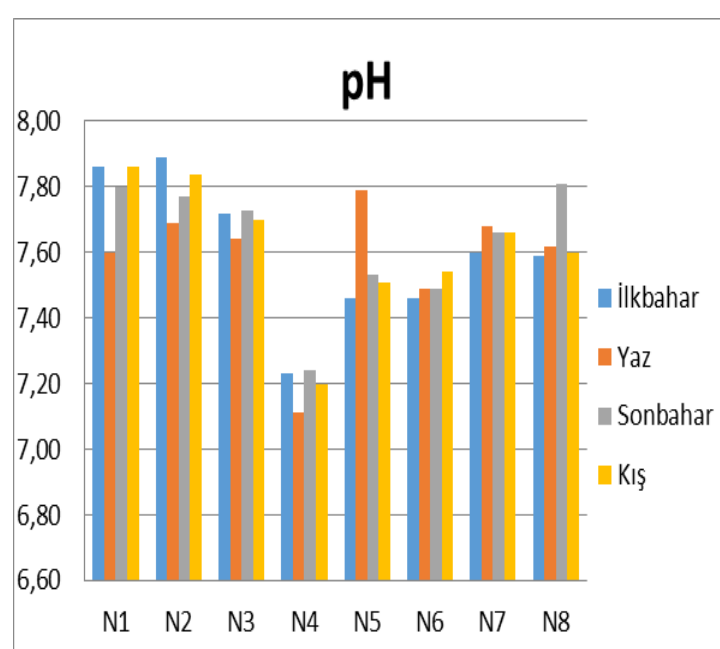

Şekil 5. pH'ın numune alma noktalarına göre mevsimsel değişimi

pH değerleri mevsimlik olarak fazla bir değişim göstermemektedir. Ancak N4 noktasında pH seviyesinin diğer noktalara göre daha düşük olması, nitrat ve nitrite bağlı olarak ortamda asiditenin yükselmiş olmasını göstermektedir.

\subsection{Nitrat ve Nitrit}

Balıklıgöl Havzası'ndan alınan numunelerde nitrat ve nitrit ölçümleri yapılmıştır. Buna göre elde edilen nitrat ve nitrit sonuçlarının SPSS'de yapılmış minimum ve maksimum değerleri (Çizelge 2) tüm mevsimler baz alındığında nitrat için en düşük değer N3 noktasında $1,5 \mathrm{mg} / \mathrm{L}$ en yüksek N4 noktasında $15,9 \mathrm{mg} / \mathrm{L}$ olarak ölçülmüştür. Nitrit için en düşük değer N3 noktasında $0,01 \mathrm{mg} / \mathrm{L}$ en yüksek değer N4 noktasında $0,2 \mathrm{mg} / \mathrm{L}$ olarak tespit edildiği görülmektedir. 
Çizelge 2. Nitrat ve nitrit parametrelerinin minimum ve maksimum değerleri

\begin{tabular}{|c|l|c|c|c|c|c|c|c|c|}
\hline No & Numune noktaları & \multicolumn{4}{|c|}{$\mathrm{NO}_{3} \mathrm{mg} / \mathrm{L}$} & \multicolumn{4}{c|}{$\mathrm{NO}_{2} \mathrm{mg} / \mathrm{L}$} \\
\hline \multirow{2}{*}{ N1 } & & En az & En çok & Ortalama & $\mathrm{SD}$ & En az & En çok & Ortalama & $\mathrm{SD}$ \\
\hline N2 & Köksüren & 2,2 & 5,3 & 3,6 & 1,3 & 0,04 & 0,09 & 0,05 & 0,02 \\
\hline N3 & Direkli & 1,4 & 10,6 & 6,5 & 2,8 & 0,02 & 0,07 & 0,04 & 0,02 \\
\hline N4 & SSK & 11,3 & 15,9 & 13,5 & 1,9 & 0,02 & 0,20 & 0,12 & 0,08 \\
\hline N5 & Beyazsaray & 4,1 & 7,6 & 5,5 & 1,5 & 0,03 & 0,05 & 0,04 & 0,01 \\
\hline N6 & Döşeme & 2,6 & 8,9 & 5,4 & 2,6 & 0,04 & 0,07 & 0,05 & 0,01 \\
\hline N7 & Aynzeliha & 2,2 & 3,9 & 3,3 & 0,7 & 0,02 & 0,04 & 0,03 & 0,01 \\
\hline N8 & Dergah & 1,9 & 5,3 & 3,7 & 1,4 & 0,03 & 0,13 & 0,09 & 0,05 \\
\hline
\end{tabular}

Nitrat ve nitritin mevsimsel olarak değişimleri Şekil 6 ve Şekil 7'de, mevsimlik olarak ortalama değerlere göre dağım haritaları da Şekil 8 ve Şekil 9'da görülmektedir.

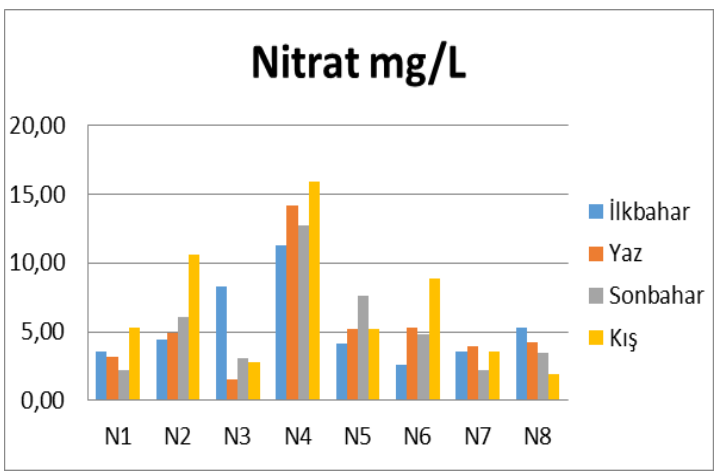

Şekil 6. Nitratın numune alma noktalarına göre mevsimsel değişimi

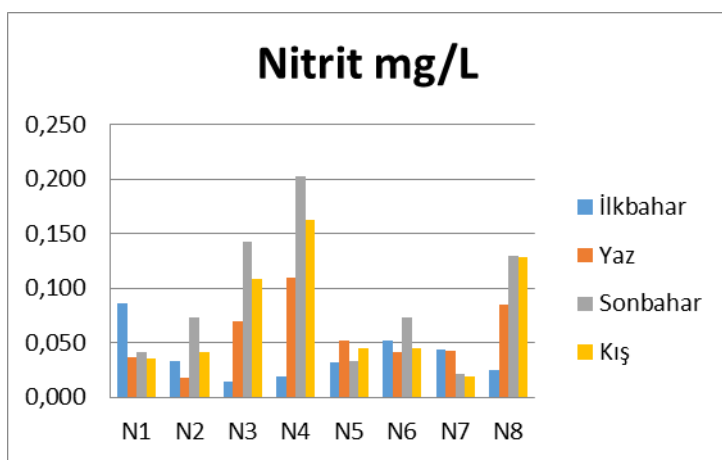

Şekil 7. Nitritin numune alma noktalarına göre mevsimsel değişimi

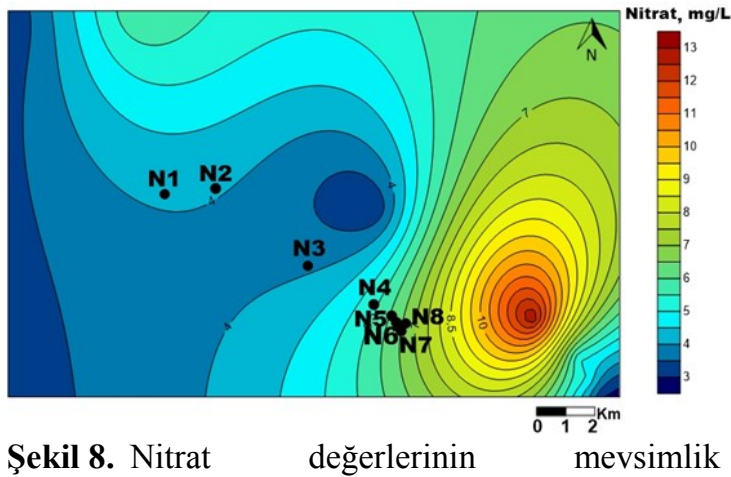
ortalamalarına göre dağılımları

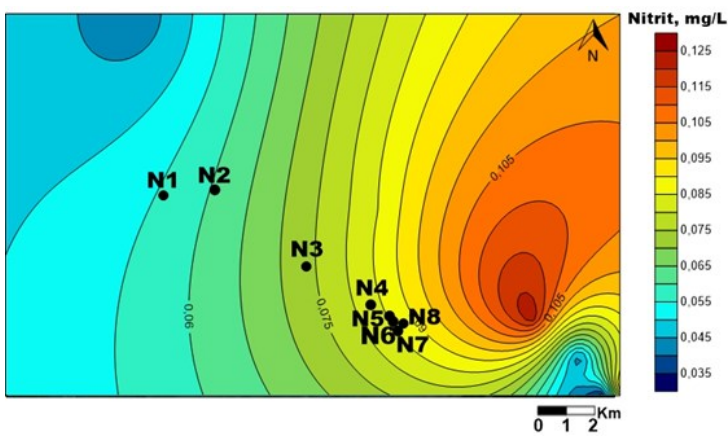

Şekil 9. Nitrit değerlerinin mevsimlik ortalamalarına göre dağılımları

Nitrit ve nitrat parametrelerinin mevsimsel değişimleri N1, N2, N3 noktalarında tarım ve hayvancılık faaliyetlerine bağlı olarak konsantrasyonlarının az miktarda değişim görülmektedir. N4 noktasından nitrit ve nitrat 
konsantrasyonlarının diğer noktalara göre daha yüksek olduğu görülmektedir. Bu noktada nitrit ve nitrat miktarlarının artış göstermesi organik kirlenmenin olduğunu, oksijen miktarının azlığının ve evsel atık su sızıntılarının olduğun göstergesidir.

\section{SONUÇ}

Her geçen gün artan insan faaliyetleri sonucunda su kaynaklarına nitrat ve nitrit kontaminasyonlarının riski artmıştır. Dünyaca ünlü Balıklıgöl ve bu gölü besleyen su kaynaklarının bulunduğu havzada yapılan çalışmada, Balıklıgöl'ün devamlılığını sürdürmek ve bu kaynaklardan içme suyu olarak kullanılanların nitrat ve nitrit düzeylerinin belirlenmesi, takip edilmesi insan ve çevre sağlığı açısından önemlidir. Havzadan alınan su numunelerinde nitrat ve nitrit varlığına rastlanmıştır. Ancak ulusal ve uluslararası standart ve siniflamalarla mukayese edildiğinde standartlara uygun olduğu ve insani tüketim açısından herhangi bir problem oluşturmayacağı sonucuna varılmıştır. Havzada genellikle tarımsal faaliyetler ve kanalizasyon sistemlerinden sızan atıksu miktarını en aza indirgeyerek ileride geri dönüşü olmayan bir kirlenmenin önüne geçilebilir. Çünkü üst havzadaki kaynaklarda olası bir kirlenme doğrudan havzanın mansabındaki tarihi ve turizm açısından önemli olan Balıklıgöl kaynağını doğrudan etkileyecektir. Dolayısıyla havza bazında ilgili kurum ve kuruluşlarca alınacak ve uygulanacak koruma önlemleri açısından bu çalışmanın katkı sağlayacağına inanılmaktadır.

\section{KAYNAKLAR}

1. Yetis, A.D., Selek, Z., 2015. Determination of Total and Fecal Coliforms of Akyatan Lagoon in Terms of Microbiological Pollution. Arabian Journal of Geosciences, 8(2), 1125-1132.
2. Vincy, MV., Brilliant, R., Pradeepkumar, AP., 2015. Hydrochemical Characterization and Quality Assessment of Groundwater for Drinking and Irrigation Purposes: A Case Study of Meenachil River Basin,Western Ghats, Kerala, India. Environ Monit Assess $187,4217$.

3. Babithesh Babu, NK., Gajendran, C., Shahul Hameed, A., James, EJ., 2015. Appraisal of Groundwater Quality for Drinking and Irrigation Purposes in Nambiyar River Basin, Tamil Nadu, India. Water Resources, 42(4), 553-562.

4. Yetiş, R., 2015. Şanlıurfa Balıklıgöl Havzası Karstik Su Kaynaklarının Kalite Parametrelerinin İncelenmesi. Harran Üniversitesi, Fen Bilimleri Enstitüsü, Çevre Mühendisliği Ana Bilim Dalı, Yüksek Lisans Tezi. Şanlıurfa.

5. USGS(2017).https://water.usgs.gov/nawqa/nutr ients/pubs/wcp_v39_no12/. Accessed 2 May 2017.

6. Durmaz, H., Ardıç M., Aygün O., Genli N., 2007. Sanlıurfa ve Yöresindeki Kuyu Sularında Nitrat ve Nitrit Düzeyleri. YYÜ Vet. Fak. Dergisi, 18(1), 51-54.

7. Oruç, H.H., Ceylan, S., 2001. Bursa'da Tüketilen Bazı Sebzelerde Nitrat ve Nitrit. J Fac Vet Med 20, 17-21.

8. Selek, Z., Yetis, A.D., 2017. Assessment of Nitrate Contamination in a Transnational Groundwater Basin: A Case Study in the Ceylanpinar Plain, Turkey. Environ Earth Sci (2016) 76, 698.

9. Demir, A., 2008. Akyatan Lagününde Tuzluluk ve Bazı Kirlilik Düzeylerinin Saptanarak Coğrafi Bilgi Sistemi Destekli Dağılımlarının Belirlenmesi, Çukurova Üniversitesi, Fen Bilimleri Enstitüsü, Çevre Mühendisliği Ana Bilim Dalı, Yüksek Lisans Tezi. Adana.

10. Türkdoğan, M.K., Testereci, H., Akman, N., Kahraman, T., Kara, K., Tuncer, İ., Uygan, İ., 2003. Dietary Nitrate and Nitrite Levels in an Endemic Upper Gastrointestinal (Esophageal and Gastric) Cancer Region of Turkey. Turk J Gastroenterol, 14(1), 50-53.

11. Oruç, H.H., Ceylan, S., 2001. Bursa Yöresinde Sığırların Yemlerinde, İçme Sularında ve Rumen İçeriğinde Nitrat, Nitrit ve Kanda 
Methemoglobin Düzeylerinin Araştırılması. J Fac Vet Med, 20, 25-32.

12. Knobeloch, L., Salna, B., Hogan, A., Postle, J., Anderson, H., 2000. Blue Babies and Nitratecontaminated Well Water. Environ Health Perspect. $2000 \mathrm{Jul}$; 108(7), 675-678.

13. WHO, 2011. The Guidelines for DrinkingWater Quality, fourth edition, WHO, India.

14. Yesilnacar, M,I., Gulluoglu, M,S., 2008. Hydrochemical Characteristics and the Effects of Irrigation on Groundwater Quality in Harran Plain, GAP Project, Turkey. Environ Geol 54, 183-196.

15. DSI (The General Directorate of State Hydraulic Works) 2012. Şanlıurfa Balıklıgöl Karst Hidrojeolojisi Etüt Raporu. T.C. Enerji ve Tabii Kaynaklar Bakanlığı, Devlet Su İşleri Genel Müdürlüğü, Jeoteknik Hizmetler ve Yeraltı suları Dairesi Başkanlığı, Karst Araştırma Şube Müdürlüğü, Ankara (In Turkish).

16. Polat, A., 2012. The Geology of Northern Adiyaman Province and its Petroleum Possibilities. Çukurova Üniversitesi, Fen Bilimleri Enstitüsü, Jeoloji Mühendisliği Ana Bilim Dalı, Yüksek Lisans Tezi. Adana (In Turkish)

17. Yazar, B.B., 2009. Investigation of Subsurface Geology and Petroleum Possibilities of Mardin Group Carbonates in Southern AdiyamanKahta Area (Çalgan-Karaköprü-Alg̀dağ Region). Ankara Üniversitesi, Fen Bilimleri Enstitüsü, Jeoloji Mühendisliği Anabilim Dalı, Yüksek Lisans Tezi. Ankara.

18. Bozkurt, Ş., 2013. Şanlıurfa Balıklıgöl Havzasının Sürdürülebilir Bir Şekilde Kullanımının Sağlanması, DSİ XV. Bölge Müdürlüğü, Eğitim notu. Şanlıurfa.

19. APHA, AWWA, WEF 1998. Standard Methods for the Examination of Water and Wastewater. L.S. Clesceri, A.E. Greenberg and A.D. Eaton (Eds), United Book Press, Baltimore, MD, USA, $20^{\text {th }}$ edn., 4-103.

20.TS 266 (TSE)(2005) Water Intended for Human Consumption, 10, Ankara.

21. US EPA, 2012. 2012 Edition of the Drinking Water Standards and Health Advisories. EPA 822-S-12-001 Office of Water U.S.
Environmental Protection Agency Washington, DC.

22. Şahinci, A., 1991. Doğal Suların Jeokimyası, Reform Matbaas1, 548, İzmir.

23. Disli, M., Akkurt, F., Alicilar, A., 2003. Evaluation on Water Quality of Sanliurfa Balikligol Concerning with Physical Parameters. J. Fac. Eng. Arch. Gazi Univ. 18(4), 81-88.

24. Armagan, B., Gok, N., Ucar, D., 2008. Assessment of Seasonal Variations in Surface Water Quality of the Balikligol Lakes, Sanlıurfa, Turkey. Fresenius Environmental Bulletin 17(1), 87-93.

25. Disli, M., Akkurt, F., Alicilar, A., 2004. Evaluation on Water of Sanliurfa Balikligol Concerning Chemical Parameters. J. Fac. Eng. Arch. Gazi Univ. 19(3), 287-294.

26. Sreekumar, N.V., Narayana, B., Hegde, P., Manjunatha, B.R., Sarojini, B.K., 2003. Determination of Nitrite by Simple Diazotization Method. Microchemical Journal 74, 27-32. 